\title{
Influence of structured counseling on women's selection of hormonal contraception in Israel: results of the CHOICE study
}

This article was published in the following Dove Press journal:

International Journal of Women's Health

2I August 2014

Number of times this article has been viewed

\author{
Arie Yeshaya' \\ Amos Ber ${ }^{2}$ \\ Daniel S Seidman ${ }^{3}$ \\ Bjorn J Oddens ${ }^{4}$ \\ 'Department of Obstetrics and \\ Gynecology, Rabin Medical Center, \\ Petah Tikva, ${ }^{2}$ Maccabi Health Services, \\ Tel Aviv, Israel; ${ }^{3}$ Department of \\ Obstetrics and Gynecology, Sacker \\ School of Medicine, Tel Hashomer, \\ Israel; ${ }^{4} \mathrm{Global}$ Medical Affairs, MSD, \\ Oss, the Netherlands
}

Correspondence: Arie Yeshaya

Department of Obstetrics and

Gynecology, Rabin Medical Center,

39 Jabotinski St., Petah Tikva 49100, Israel

Tel +972 37324682

Fax +97235496017

Email yeshaya.a.j@0।2.net.il
Background: The multinational CHOICE (Contraceptive Health Research Of Informed Choice Experience) study evaluated the effects of structured counseling on women's contraceptive decisions, their reasons for making those decisions, and their perceptions of combined hormonal contraceptive $(\mathrm{CHC})$ methods in eleven countries. The aim of this paper to present data from the 1,802 women participating in Israel's CHOICE program.

Methods: Women (aged 17-40 years) who consulted their health care providers about contraception and who would consider a $\mathrm{CHC}$ method qualified to participate. After indicating their intended $\mathrm{CHC}$ method, the women received counseling about the daily pill, weekly patch, and monthly vaginal ring. After counseling, the women completed a questionnaire about their contraceptive decisions.

Results: Before counseling, 67\%, 6\%, and 5\% of women (mean age 27 years) intended to use the pill, patch, or ring, respectively. Counseling significantly influenced the women's CHC choice, with $56 \%, 12 \%$, and $23 \%$ of women selecting the pill, patch, or ring $(P<0.0001$ for all contraceptive methods versus before counseling). Logistic regression analysis suggested that age significantly increased the probability of switching from the pill to the ring.

Conclusion: Although the pill was the most popular choice overall, counseling appeared to influence Israeli women's contraceptive decisions, with significantly more women selecting the patch. More than four times as many women selected the ring after counseling than before counseling.

Keywords: combined hormonal contraceptive, counseling, contraceptive ring, contraceptive patch, oral contraceptive pill

\section{Introduction}

Combined hormonal contraceptives $(\mathrm{CHC})$ consisting of a progestagen and ethinyl estradiol are the most popular forms of reversible contraception, and include the daily pill, transdermal weekly patch, and monthly vaginal ring, with the pill being the most prevalent $\mathrm{CHC}$ method in Israel, the USA, and Europe (used by $13 \%, 16 \%$, and 21\%, respectively, of all women in the reproductive age group who are married or in a relationship). ${ }^{1,2}$ Each of these contraceptive methods have high efficacy when used properly; however, efficacy during typical use is much lower, primarily because of poor compliance with the method chosen. ${ }^{3}$ While clinical data are limited, recent studies have attempted to assess the issue of $\mathrm{CHC}$ compliance in clinical trials. A recent Cochrane review examined 18 randomized clinical trials comparing a transdermal contraceptive patch (six studies) or a contraceptive vaginal ring (12 studies) with combination oral contraceptives. ${ }^{4}$ Patch users showed better compliance and were less likely to have 
missed days of therapy than pill users, while data for vaginal ring users was divided.

Based on these data, contraceptive compliance can be regarded as one of the most important considerations for helping women avoid unintended pregnancy. Contraceptive counseling (ie, providing fair and balanced information about the available contraceptive options, tailored to the woman's needs and preferences, allowing her to make an informed choice), is thought to improve acceptance, compliance, and user satisfaction. ${ }^{5,6}$ Further, adherence is increased if the woman is allowed to make a choice about which contraceptive to use and when this choice is revisited at follow-up clinic visits. ${ }^{7}$ Providing written information to women is also thought to help improve compliance. ${ }^{8}$

A cross-sectional Spanish study (TEAM-06) examined the reasons why women selected the pill, patch, or ring, ${ }^{9}$ given that these $\mathrm{CHC}$ methods are similar in efficacy, safety, and tolerability. ${ }^{3,10-12}$ As part of the TEAM-06 protocol, women were counseled about these three methods and given an informational leaflet to reinforce the verbal information. After counseling, the women were surveyed to ascertain the reasons for their choices. A similar study, IMAGINE (IMpacto de um programa de informAção pelos GINEcologistas na contracepção hormonal combinada, em Portugal), was performed in Portugal. ${ }^{13}$ In both studies, the pill was the most preferred method before counseling; however, after counseling, a significantly higher number of women chose other methods, eg, the patch or ring, indicating that the selected method better fit their life circumstances.

The multinational CHOICE (Contraceptive Health Research of Informed Choice Experience) study was designed to examine contraceptive choices in women who asked for a $\mathrm{CHC}$ method before and after contraceptive counseling in eleven countries. ${ }^{14}$ The CHOICE study included women who expressed an interest in CHCs. They were counseled on the pill, patch, and ring, ie, methods that have similar efficacy and safety but differ in route of hormone delivery and frequency of use.

The overall results of CHOICE confirmed the findings of TEAM- $06^{9}$ and IMAGINE, ${ }^{13}$ and indicated that counseling encouraged women to learn about and choose alternative forms of contraception that may be different from the method intended before consulting with their health care practitioner, including the pill, patch, and ring, as well as other methods. However, considerable differences were noted among the various countries included in CHOICE. For example, the number of women who changed to the ring was more pronounced in central and eastern European countries (Czech
Republic, Poland, Russia, Slovakia, Ukraine) than in northern European countries (Austria, Belgium, the Netherlands, Sweden, Switzerland). ${ }^{14}$ After counseling, one of the largest decreases in intended pill use measured in the CHOICE study occurred in Israel (from $67 \%$ to $56 \%$, a decrease of $11 \%$ ). In Belgium, Russia, Sweden, Switzerland, and Ukraine, the proportion of women choosing the pill, patch, or ring increased after counseling when compared with the proportion intending to use that method before counseling, with new patch and ring users switching primarily from the group who initially had no clear preference for any of the three CHC methods.

Our aim was to focus on results from the CHOICE study obtained for women in Israel and to provide details about the choices of Israeli women after contraceptive counseling on the use of CHC. The literature on contraceptive choices in Israel is limited. In a previous study reporting data from eleven countries, we presented high-level results and mainly compared central and eastern European countries with northwestern European countries, whereas Israel was the only Middle East country involved in the study. ${ }^{14} \mathrm{CHOICE}$ is the largest study to date addressing this topic in Israel.

\section{Materials and methods}

CHOICE was a cross-sectional, multinational study conducted in eleven European countries, including Israel. The overall program was supervised by an international steering committee and was endorsed by the European Society of Contraception and Reproductive Health. The study has been described previously in detail. ${ }^{14}$ The 1,802 Israeli women represent approximately $10 \%$ of the total CHOICE sample $(\mathrm{n}=18,787)$.

In brief, potentially interested health care professionals (HCPs) were identified by the national Israeli steering committee. They were visited individually for a discussion of the study or participated in an investigators' meeting. The study protocol, procedures, counseling leaflet, and questionnaires were reviewed in detail in these visits and meetings. In addition, the HCPs were asked to review an online training module about structured contraceptive counseling, developed in collaboration with Professor Johannes Bitzer, president of the European Society of Contraception and Reproductive Health. Women aged 15-40 years were eligible for study entry when consulting these HCPs for starting or restarting a combined method of $\mathrm{CHC}$ and if they expressed interest in at least one of three $\mathrm{CHC}$ methods (pill, patch, or ring) or switching between combined oral contraceptive pills. All women were required to give their informed consent; only 
women who understood the information given to them by their HCPs were eligible to participate. In Israel, women aged 17-40 years participated, with parental consent secured for younger women.

Before a woman received any information or counseling, the $\mathrm{HCP}$ recorded which of the $\mathrm{CHC}$ methods the woman was considering or had requested. During the same clinic visit, the HCP then counseled the woman about the pill, patch, or ring (or other methods if more suitable for that individual) and noted whether there were reasons why $\mathrm{CHC}$ methods might not be suitable.

During the structured counseling session, the HCP usually used a counseling leaflet that described the characteristics of the three CHC methods (pill, patch, or ring) ${ }^{14}$ The counseling session included discussion of the mode of action, instructions for use, and potential risks, effectiveness, and benefits of each method. During the session, if the HCP determined that an alternative contraceptive method was more appropriate (other than the pill, patch, or ring) for particular women, the HCP counseled as appropriate and these women remained in the study. The objective of the study was to assess the final contraceptive decision of women who initially had an interest in a CHC method; consequently, the choices of women who opted after counseling for a non- $\mathrm{CHC}$ method were also recorded. At the start of the study, the HCPs provided information about their specialty, age, and most frequently recommended contraceptive method. After each counseling session, both the HCPs and the women participants completed a questionnaire. The HCPs recorded whether the leaflet was used during the session and when a medical reason or contraindication excluded the choice of a CHC method. The women completed 18 multiple choice and open-ended questions, including demographic and gynecologic information, the method actually chosen (pill, patch, ring, other, or undecided), and reasons for choosing this method, and perceptions about the three contraceptive methods. The woman's questionnaire took approximately 10 minutes to complete.

\section{Statistics and sample size}

The statistical objectives of the study have been described previously, ${ }^{14}$ and were to identify any significant changes in the proportions of preferred versus chosen contraceptive methods after counseling. We aimed to determine whether the choice of patch or ring increased significantly after counseling compared with method preferences before counseling.

A target sample size of at least 1,500 women was required to achieve a precision of $2 \%$, assuming that $10 \%$ of the women would select the patch and $10 \%$ would select the ring after counseling. This sample size was estimated to be sufficient to detect an increase of $3 \%$ in either ring or patch choice (compared with precounseling intended ring/patch selection) with a power of above $90 \%$ and a one-sided significance level of $1.25 \%$. The sample size was then increased by approximately $20 \%$ to compensate for nonevaluable questionnaires and erroneous entry into the study, resulting in a target sample size of 1,850 women. For the post counseling preference prevalence rates, simultaneous two-sided $95 \%$ confidence intervals were calculated based on a five-cell multinomial probability distribution. ${ }^{15}$ The statistical significance of the postcounseling versus precounseling differences in choice was assessed using McNemar's test with a two-sided significance level of $2.5 \%$ (because two comparisons [for the patch and for the ring choice] were made). All other analyses were exploratory and a two-sided significance level of $5 \%$ was used.

The questionnaire included questions about the women's perceptions of the efficacy, safety, and use aspects of the three CHC methods after counseling. To assess the association between these perceptions and the likelihood of choosing the method concerned, the probability of choosing the method was modeled using a binomial regression model against woman's age and agreement or disagreement with each of the following eight perception statements (translated from the original Hebrew) for each method (with the categories "no opinion" and "do not know" as a combined reference category):

- the (pill, patch, ring) prevents pregnancy effectively

- the (pill, patch, ring) has many side effects

- the (pill, patch, ring) can be dangerous to health

- the (pill, patch, ring) is easy to use

- starting a new (pill, patch, ring) is easy to forget

- the (pill, patch, ring) allows regular menstrual bleeding

- the (pill, patch, ring) protects against certain forms of cancer

- many women use it (pill, patch, ring).

In addition, three multiple logistic regression models were fit to investigate which background characteristics of women and the HCP were associated with a probability of switching from the pill (as precounseling preference) to another method, the probability of switching from a $\mathrm{CHC}$ method to the patch, and the probability of switching to the ring. The relevant women's characteristics included age, educational level, employment status, plan to have (more) children, unintended pregnancies, steady relationship, and last (main) contraceptive method. The characteristics of the HCPs included age and the most frequently recommended contraceptive method. The predictive factors were selected in a stepwise fashion, and the age of the woman was always included in the models as a covariate. For 
the stepwise procedure, significance levels of 0.20 and 0.05 were used for inclusion in and exclusion from (respectively) the model. The logistic regression models were fit using the logistic procedure in SAS version 9.1 (SAS Institute Inc., Cary, NC, USA). Women with missing data were excluded from the analysis. In the various analyses, about $7 \%$ of women had some missing data on the covariates and therefore were dropped from the analysis. Given that the number of women with missing data was small, we did not compare the choices of these women with those for whom the data were complete.

\section{Results}

\section{Health care practitioners}

All 110 HCPs who included subjects in this study and filled out the questionnaire were gynecologists. Most HCPs were male $(59 \%)$ and were either in the 40-49-year age range $(34 \%)$ or in the $50-59$-year age range $(49 \%)$. Only $4 \%$ reported that their most frequently recommended $\mathrm{CHC}$ method was an alternative to the pill.

Before counseling, HCPs reported that $67 \%$ of women thought they might want to use the pill, $6 \%$ the patch, $5 \%$ the ring, $6 \%$ a different method, and 16\% had no specific preference regarding which $\mathrm{CHC}$ method was best for them. If the woman had no specific preference, the HCP thought that the pill, patch, or ring was most appropriate in $16 \%$, $8 \%$, and $17 \%$ of cases, respectively. HCPs reported using the counseling leaflet in $69 \%$ of counseling sessions. In $31 \%$ of cases, the leaflet was not used or distributed because the verbal counseling was deemed sufficient, and the patient indicated that they understood the contraceptive options and did not want to receive the leaflet.

\section{Women requesting $\mathrm{CHC}$}

As part of CHOICE, 1,802 Israeli women were counseled about $\mathrm{CHC}$ methods, and 1,749 answered the questions on contraceptive choice both before and after counseling. Of the women in this study, 58\% were between 21 and 30 years (age range 17-40 years, Table 1). Most of the women had advanced education beyond high school, $77 \%$ were employed full-time or part-time, and almost half (48\%) had used the daily pill as their last (main) contraceptive method. Most of the women were in a steady relationship (85\%) and planning to have (more) children (76\%). Only 19\% had a prior history of abortion and/or unintended pregnancy.

\section{Impact of counseling on method chosen}

Overall, $40 \%$ of women changed their intended method of contraception after counseling, whereas $60 \%$ did not. After
Table I Women's characteristics

\begin{tabular}{|c|c|c|}
\hline Parameter & $\mathbf{n}$ & $\%$ \\
\hline Total & 1,802 & \\
\hline Age (mean $\pm S D)$, years & $26.7 \pm 6.0$ & \\
\hline $17-20$ & 272 & 15 \\
\hline $21-25$ & 589 & 33 \\
\hline $26-30$ & 443 & 25 \\
\hline $31-35$ & 296 & 16 \\
\hline $36-40$ & 187 & 10 \\
\hline Missing* & 15 & \\
\hline \multicolumn{3}{|l|}{ Highest educational level } \\
\hline Primary school & 51 & 3 \\
\hline High school & 612 & 34 \\
\hline Advanced, non-university & 469 & 26 \\
\hline University & 660 & 37 \\
\hline \multicolumn{3}{|l|}{ Employment status } \\
\hline Unemployed & 410 & 23 \\
\hline Part-time & 531 & 30 \\
\hline Full-time & 845 & 47 \\
\hline \multicolumn{3}{|l|}{ Number of children } \\
\hline 0 & 433 & 38 \\
\hline I & 205 & 18 \\
\hline 2 & 248 & 22 \\
\hline 3 & 166 & 14 \\
\hline$>3$ & 99 & 9 \\
\hline Missing* & 651 & \\
\hline \multicolumn{3}{|l|}{ Last contraceptive method } \\
\hline Never used contraception & 144 & 8 \\
\hline Combined oral contraceptive & 844 & 48 \\
\hline Weekly patch & 57 & 3 \\
\hline Contraceptive ring & 61 & 4 \\
\hline Progestagen-only pill & 121 & 7 \\
\hline LNG-IUS & 23 & 1 \\
\hline Injectable & 6 & $<1$ \\
\hline Contraceptive implant & 4 & $<1$ \\
\hline IUD & 79 & 5 \\
\hline Condom & 379 & 22 \\
\hline Natural family planning & 45 & 3 \\
\hline
\end{tabular}

Note: *Did not answer the question.

Abbreviations: IUD, intrauterine device; LNG-IUS, levonorgestrel intrauterine system; SD, standard deviation.

counseling, the proportion of women choosing the patch or ring increased significantly $(P<0.0001)$ when compared with the proportion preferring the method used before counseling, whereas the proportion choosing the pill significantly decreased (Figure 1A).

Most women who chose the pill after counseling had intended to use the pill; however, $42 \%$ of women who chose the patch and $46 \%$ who chose the ring originally (ie, precounseling) intended to use the pill (Figure 1B). Before counseling, 287 women were undecided as to which method to choose. Of these women, 34\% chose the pill, 33\% the ring, and $19 \%$ the patch, whereas $9 \%$ (25 women) remained undecided after counseling. In total, 67 women were undecided after counseling (42 women who initially intended to use 
A

Intended and chosen contraceptive methods

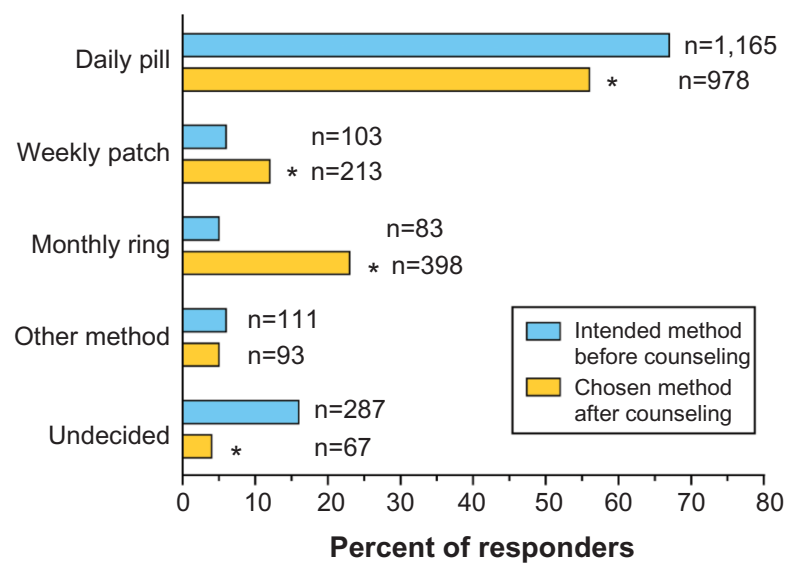

${ }^{*} P<0.0001$ for difference of proportions intended versus chosen

B

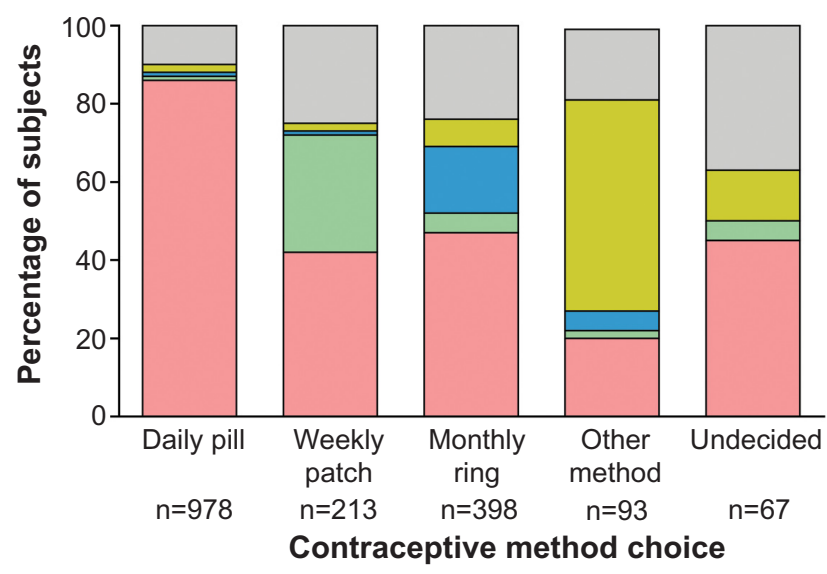

$\square$ Daily pill $\square$ Weekly patch $\square$ Monthly ring $\square$ Other $\square$ Not decided

Figure I Effect of counseling on contraceptive method in 1,749 women completing both intended and chosen portions of the questionnaire $(\mathbf{A})$. Method chosen after counseling by method intended before counseling (B).

Notes: Each column includes the proportions of those who switched from specific intended methods as well as those who remained with their intended method. "Other" includes forms of contraception other than pill, patch or ring. Data are from women completing both intended and chosen portions of the questionnaire.

the pill or another method indicated that they were "undecided" after counseling, Figure 1B). The most cited reasons in this group were "want to discuss with partner" $(52 \%)$ and "want to get further information (including information on other methods)" (33\%). In the postcounseling questionnaire, women answered a number of questions regarding their opinions about specific methods. Figure 2 presents the women's opinions about combined hormonal contraceptives after counseling. Approximately $80 \%-90 \%$ of women agreed with the statements indicating that the pill effectively prevents pregnancy, is easy to use, results in regular bleeding, and
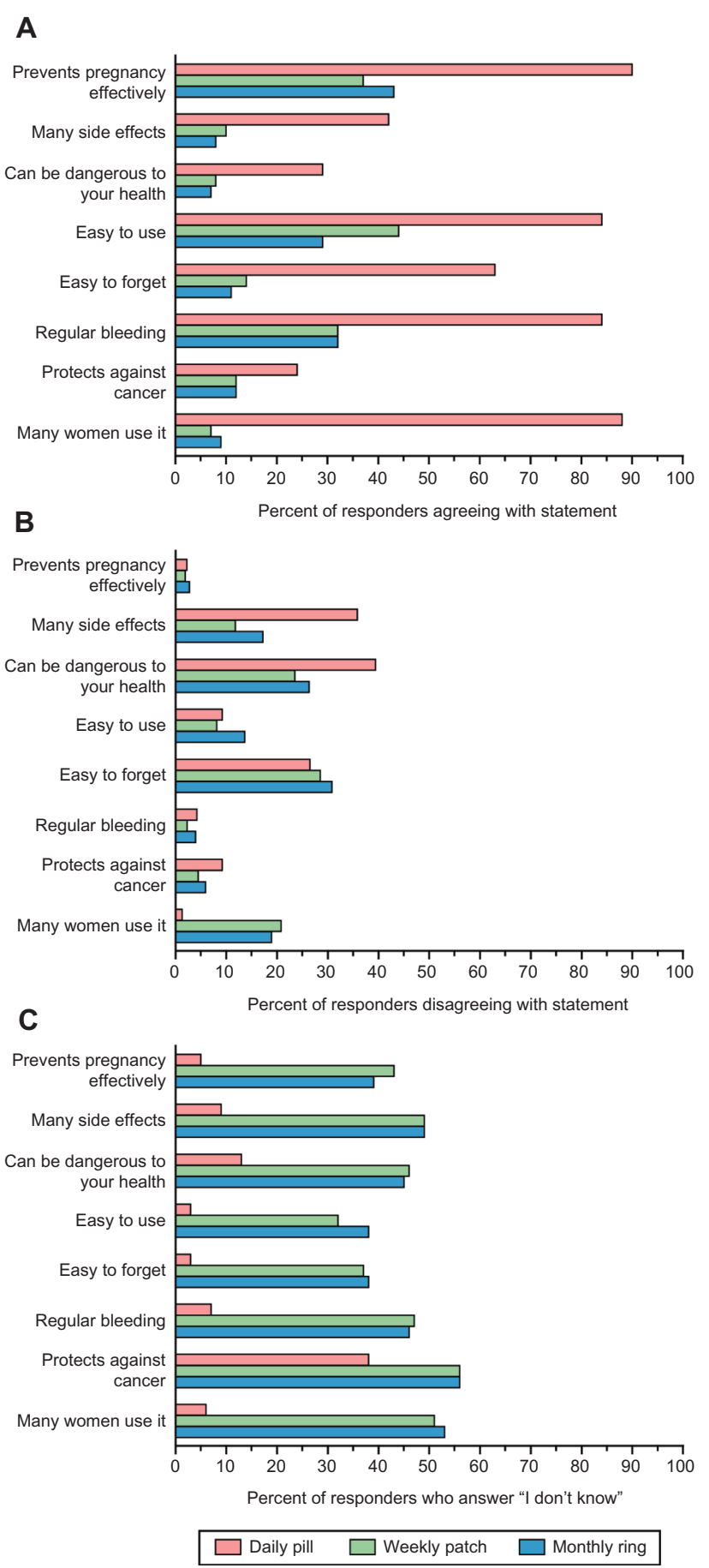

Figure 2 Women's opinions about combined hormonal contraceptives after counseling. Percent of responders who agreed (A), disagreed (B), or answered "I don't know" (C) to statement.

many women use it. Approximately $40 \%$ of women agreed with statements that the patch or ring were effective contraceptives and almost half of the women answered "I don't know" when answering many of the same questions about the patch or ring after counseling. The participants were asked to rate three qualities related to the counseling they received from their HCPs. They were asked whether the counseling 
was useful, complete, and fair and balanced. The majority of the participants rated these qualities highly, reporting that the counseling was very useful, very complete, and very fair and balanced (Figure 3).

\section{Relationship between method selection and woman's age}

More than $70 \%$ of women in the youngest age group (17-20 years) chose the pill after counseling. In contrast, less than half of women aged 31 years and older chose the pill (Figure 4). Interestingly, a higher proportion of women in the older age groups chose the ring than in the younger age groups. There appeared to be no such relationship with regard to the women who chose the patch.

\section{Models for choice of different methods}

The probability of choosing the pill, patch, or ring after counseling were separately modeled on the responses to the eight opinion questions and woman's age using a binomial regression analysis (Table 2 ). The probability of choosing any of the three methods was significantly increased if the woman strongly agreed/agreed with the statements that the method prevented pregnancy, was easy to use, and allowed regular menstrual bleeding compared with women with "no opinion/do not know". The probability of choosing the pill was significantly reduced in women who strongly agreed/ agreed with the statements "the pill has many side effects" and "the pill can be dangerous to your health". However, strongly agreeing/agreeing with statements about side effects and the dangers of the patch or ring did not significantly affect the probability of choosing these two methods as compared with the probability that women who replied "no opinion/do not know" would choose them. Women who thought the pill was "easy to forget" had a much lower probability of choosing the pill than women with "no opinion/ do not know".

The logistic regression model for the subgroup of women who intended to use the pill before counseling showed an odds ratio for changing from the pill to another method versus not to change from the pill of 1.42 per 5 -year increase in age $(P<0.0001)$, indicating that increasing age significantly increases the probability of changing from the pill. Also, based on the binomial regression analysis, age had a significant impact on the probability of choosing the ring

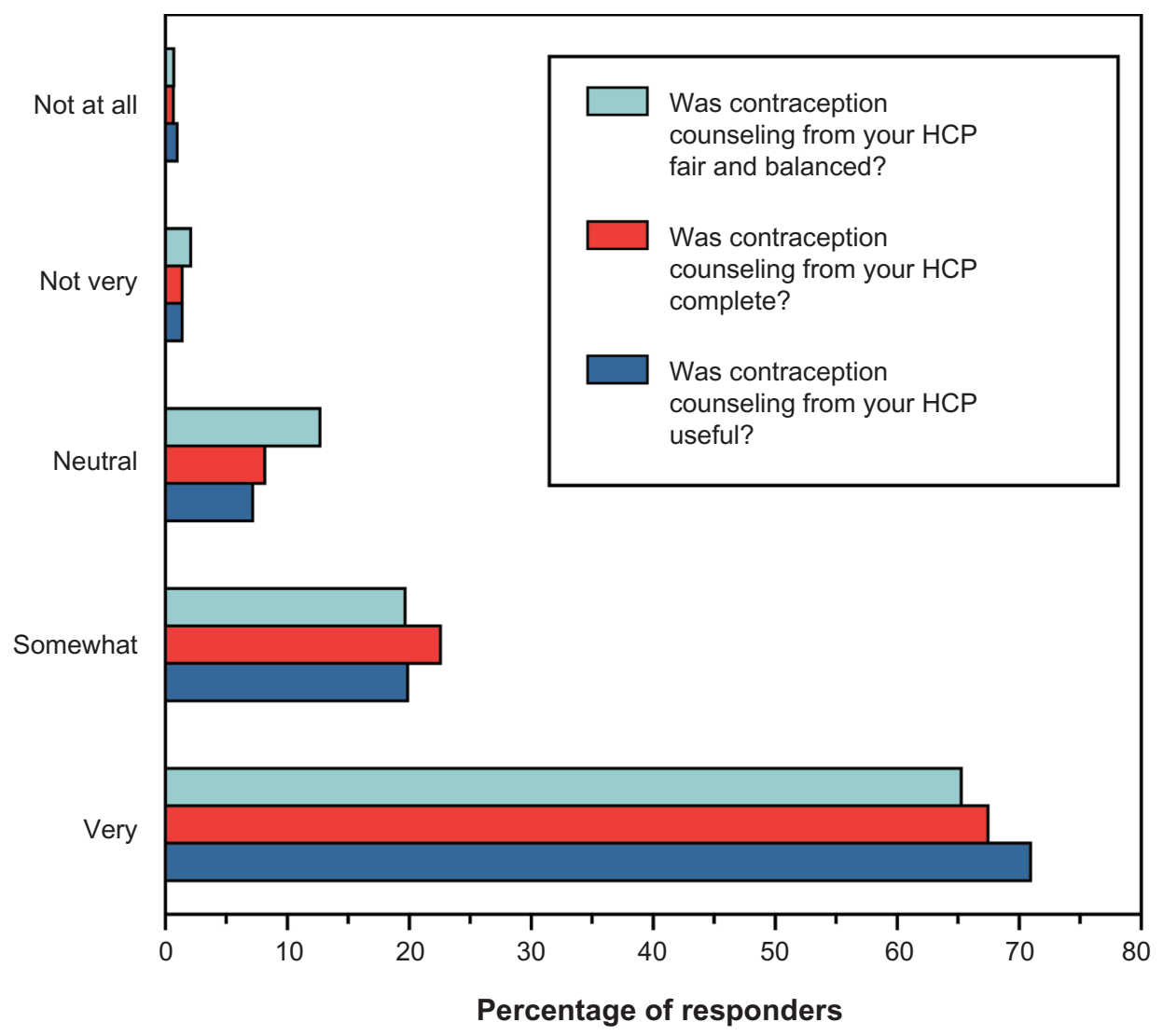

Figure 3 Rating of counseling provided by HCP.

Abbreviation: $\mathrm{HCP}$, health care provider. 


\section{Chosen method}

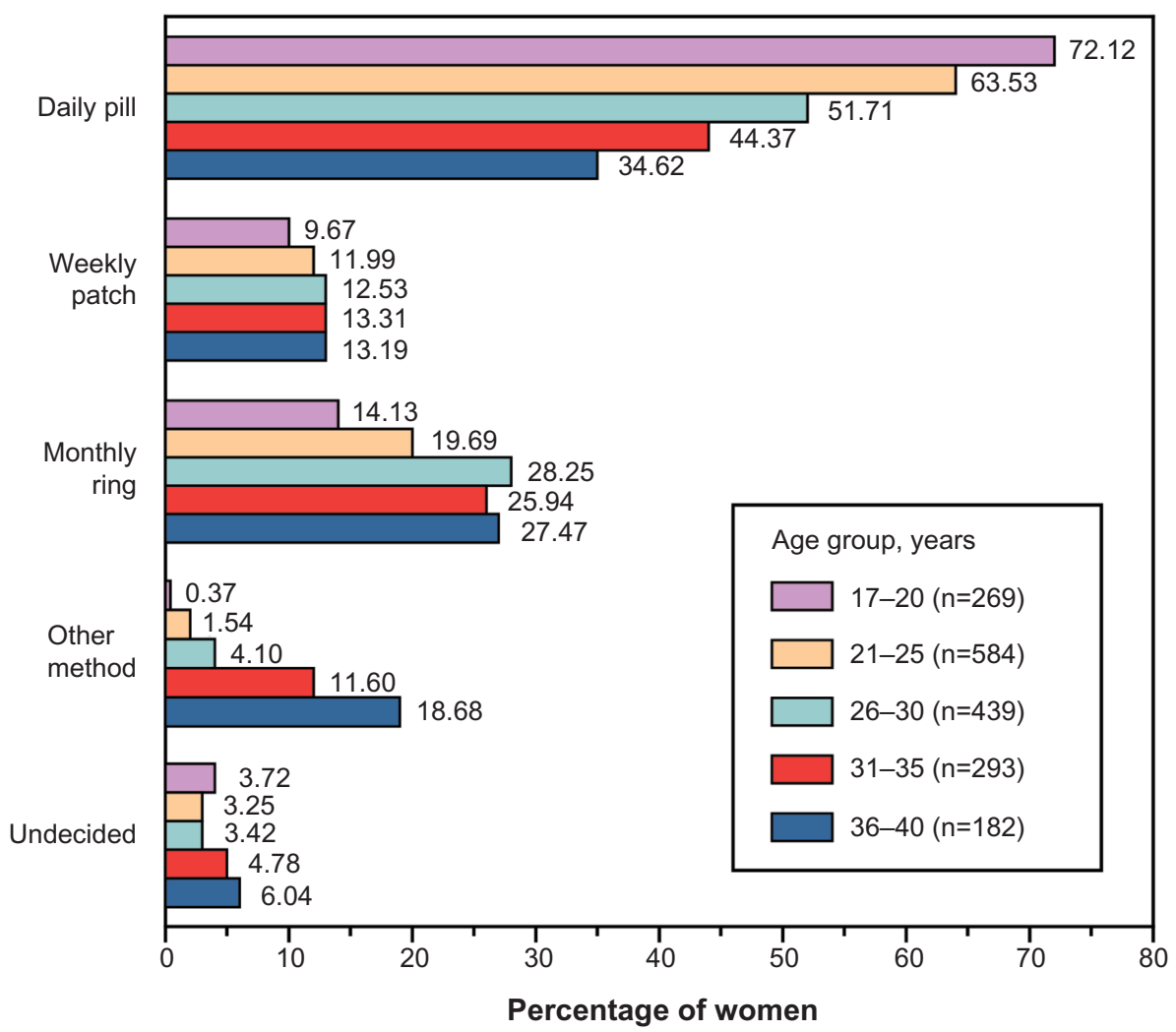

Figure 4 Relationship between the woman's age and the method chosen after counseling.

Note: Data are from women completing the questionnaire. Percentages shown are with respect to age subgroups.

among women who did not intend to use the ring prior to counseling, ranging from $2.3 \%$ to $4.2 \%$ per 5 -year increase in age. The associated odds ratio was 1.21 per 5 -year increase in age $(P=0.0003)$. Age did not have a significant impact on the probability of choosing the patch.

None of the other predictive factors (woman's educational level, employment status, plan to have [more] children, unintended pregnancies, steady relationship and last [main] contraceptive method, the age of the HCP, and most frequently recommended contraceptive method) were associated with the probability of changing from the pill or change to the patch or ring.

\section{Discussion}

This single-country analysis of data from the multinational cross-sectional CHOICE study ${ }^{14}$ confirms that structured counseling has a significant impact on a woman's choice of contraceptive method in Israel. Before counseling, most Israeli HCPs and most Israeli women assumed that the pill would be their method of choice. Although the pill remained the most popular choice, the numbers of women choosing the patch and ring increased significantly after structured counseling; this was also one of the key findings of the larger CHOICE study.

The HCPs were encouraged in the CHOICE study to use an information leaflet that described the pros and cons of the pill, patch, and ring, unless there were contraindications or medical reasons not to explore use of these $\mathrm{CHC}$ methods. In the eleven countries, $86 \%$ of HCPs used the leaflet when counseling the women. In contrast, this number was considerably lower $(69 \%)$ in Israel, but in the $31 \%$ of cases where the leaflet was not used, the HCPs noted that verbal counseling was deemed sufficient and that the patient understood the contraceptive options and did not want to receive the leaflet. Medical reasons or contraindications were only reported for $2.7 \%$.

Age was an important factor influencing a woman's decision. In Israel, the probability of a woman choosing the pill decreased and the probability of choosing the ring increased when women's choices were evaluated in 5-year age increments. A similar trend was noted in the Spanish TEAM-06 study ${ }^{9}$ and in Belgian women included in the CHOICE study. ${ }^{16}$ More than $70 \%$ of the youngest women in the study (aged 17-20 years) opted for the pill. Most women 
Table 2 Estimated impact of the woman's opinion on the probability to choose a method based on her perceptions post counseling of eight questions about the contraceptive method using binomial regression modeling

\begin{tabular}{|c|c|c|c|c|}
\hline Question & $\begin{array}{l}\text { Relative probability* to } \\
\text { choose after counseling } \\
\text { if strongly agree/agree } \\
\text { Percent estimate }\end{array}$ & $P$-value & $\begin{array}{l}\text { Relative probability* to } \\
\text { choose after counseling if } \\
\text { strongly disagree/disagree } \\
\text { Percent estimate }\end{array}$ & $P$-value \\
\hline \multicolumn{5}{|l|}{ Pill } \\
\hline Prevents pregnancy & 10.0 & 0.029 & -11.1 & 0.2 \\
\hline Has many side effects & -18.9 & $<0.0001$ & 2.6 & 0.4 \\
\hline Can be dangerous & -16.7 & $<0.0001$ & 1.7 & 0.5 \\
\hline Easy to use & 19.9 & $<0.0001$ & -15.4 & 0.005 \\
\hline Easy to forget & -14.8 & 0.0001 & 10.0 & 0.013 \\
\hline Gives regular menstrual bleeding & 10.6 & 0.0055 & -7.6 & 0.3 \\
\hline Protects against cancer & 0 & 1.0 & -10.3 & 0.011 \\
\hline Many women use it & 3.0 & 0.4 & -14.4 & 0.2 \\
\hline \multicolumn{5}{|l|}{ Patch } \\
\hline Prevents pregnancy & 13.6 & $<0.0001$ & -1.3 & 0.8 \\
\hline Has many side effects & -0.5 & 0.8 & 20.1 & $<0.000$ I \\
\hline Can be dangerous & 1.9 & 0.5 & 13.6 & $<0.0001$ \\
\hline Easy to use & 16.7 & $<0.0001$ & -2.6 & 0.1 \\
\hline Easy to forget & 2.0 & 0.3 & 16.1 & $<0.000$ I \\
\hline Gives regular menstrual bleeding & 12.6 & $<0.000 \mathrm{I}$ & -5.1 & 0.1 \\
\hline Protects against cancer & 5.0 & 0.1 & 7.7 & 0.1 \\
\hline Many women use it & 14.4 & 0.0007 & -3.2 & 0.1 \\
\hline \multicolumn{5}{|l|}{ Ring } \\
\hline Prevents pregnancy & 19.6 & $<0.0001$ & -10.6 & 0.001 \\
\hline Has many side effects & 7.3 & 0.1 & 22.0 & $<0.0001$ \\
\hline Can be dangerous & 7.6 & 0.1 & 19.0 & $<0.000$ I \\
\hline Easy to use & 29.6 & $<0.000$ I & -10.8 & $<0.000$ I \\
\hline Easy to forget & 7.2 & 0.028 & 21.1 & $<0.0001$ \\
\hline Gives regular menstrual bleeding & 23.2 & $<0.0001$ & -6.3 & 0.1 \\
\hline Protects against cancer & 17.4 & $<0.000$ I & -3.4 & 0.4 \\
\hline Many women use it & 8.9 & 0.025 & 0.1 & 1.0 \\
\hline
\end{tabular}

Note: *A positive/negative estimate indicates a higher/lower probability (\%) to choose the method compared with the reference category "no opinion/do not know".

over the age of 21 years in the study had experience with the pill. When they were offered information about the pill and the alternatives, ie, the patch and ring, a substantial proportion shifted to the ring, especially among women aged over 26 years. In the other countries, higher education level and consulting a female HCP also led to a shift to the ring, ${ }^{14}$ but this was not observed in Israel.

Women's responses to the eight statements in the questionnaire after counseling about each type of $\mathrm{CHC}$ reflect the impact of their opinions on their choice. These statements were very general (eg, "The pill" \{or ring or patch\} "has many side effects") and most women gave nuanced answers ("somewhat agree" or "somewhat disagree" versus "strongly agree"/"strongly disagree"). Agreement with statements about efficacy, ease of use, and regular bleeding were key concepts associated with increasing the probability of choosing the pill, patch, or ring. Some concern that the pill has many side effects and can be dangerous was a reason for not choosing the pill, whereas women who chose the patch or ring disagreed that these methods have many side effects and can be dangerous. The side effects of the pill and potential rare health risks were much better known than those of the patch or ring and influenced decision-making specifically about the pill.

The percentages of women who indicated "do not know" were still high for the patch and ring after counseling. In a separate analysis, ${ }^{17}$ we looked at the responses of the subset of women who had selected the method after counseling. It emerged that similarly low proportions of women who had chosen the pill, patch, or ring still indicated "do not know" in response to questions about their method. Among women who had not opted for the pill, many had an opinion about the attributes of this method, whereas many more women who had not chosen the patch or ring indicated "do not know" about these contraceptive methods. We conclude that the structured counseling included in the CHOICE study 
allowed more women to choose a method that suited their needs. Nevertheless, even after counseling about the patch and ring, women who did not choose these methods still had a limited understanding of the efficacy, safety, and ease of use of these alternatives to the pill.

National differences in results may be due to a number of factors, including counseling style, the novelty of the specific method in a country, or common preferences of the HCPs. Because of significant immigration, Israeli women represent many ethnic and religious groups. The study was not designed to look at how these differences affected acceptability of contraception. The results, however, show that even in the demographically diverse population of Israeli women, counseling appeared to influence women to pick alternatives to the pill, with more women selecting the patch and three times as many women selecting the ring after counseling than before counseling. The individual results of several other countries in the CHOICE study have been published. ${ }^{16,18-20}$

Our finding that alternatives to the pill were chosen more often in the older age groups was not due to the fact that these women were more educated or had more children, since these factors were not associated with choice of method in the logistic regression models. It is more likely these women had used the pill at some point in their lives. In a 25-year longitudinal study of contraception and pregnancies in Sweden, the pill was the most common choice in women aged younger than 29 years. ${ }^{21}$ Use of alternatives to the pill (eg, intrauterine devices or implants that require minimal user attention) increased with age and number of pregnancies. It may be that women who are somewhat older and have used the pill are looking for nondaily methods. ${ }^{22}$

The CHOICE study had a number of limitations. Each woman indicated on the questionnaire which method of contraception she chose after the counseling, but we did not validate this response against the prescription she received from her HCP. Rates of subsequent compliance and discontinuation were not assessed. Also, we need to consider that the wording of the statements for each method may have been too general, biased, or possibly inaccurate, and this may have impacted the results, although this was not verified. Lastly, this study was sponsored by Merck Sharp \& Dohme Corp., a subsidiary of Merck \& Co., Inc., Whitehouse Station, NJ, a manufacturer of oral contraceptives and the combined contraceptive vaginal ring, which may have introduced some level of bias into the results. The original design of the study and study questionnaires proposed by Merck were substantially changed by the international steering committee and national steering committee, which involved the non-Merck authors of the present publication (AY on both committees and $\mathrm{AB}$ and DS on the Israel steering committee). The international steering committee ultimately wrote the counseling leaflet used in the study and in each participating country the Israel steering committee supervised the selection of HCPs and the study execution. Nevertheless, the involvement of the sponsor led to inclusion of a number of HCPs with a favorable attitude toward the vaginal ring (as became manifest in the data about the preferences of the HCPs). Finally, our study population was limited to women who were considering CHC methods and aged 17-40 years.

\section{Conclusion}

Although the pill was the most popular choice overall, counseling appeared to influence Israeli women's contraceptive decisions, with significantly more women selecting the patch and more than four times as many women selecting the ring after counseling than they had intended before counseling. In addition, the probability of a woman choosing the ring over the pill appeared to be greater in women aged 26 years or older. Perceptions about the ease of use of a method were associated with the probability of choosing that method, and perceptions about the pill's tolerability and safety made women choose other methods.

\section{Acknowledgments}

The authors thank all HCPs who participated in this study.

\section{Disclosure}

The CHOICE study was initiated and funded by Merck Sharp \& Dohme Corp. (MSD), a subsidiary of Merck \& Co., Inc., Whitehouse Station, NJ, USA. An international steering committee (that included AY) and MSD designed the CHOICE study. Maya Marintcheva-Petrova, MSD, provided statistical support. Michael Abrahamy, MSD Israel, provided organizational and editorial assistance. Alex Loeb of Evidence Scientific Solutions, Philadelphia, PA, USA, provided editorial and medical writing assistance that was funded by MSD. AY, AB, and DS have served on medical advisory boards for MSD and occasionally serve as ad hoc lecturers for MSD. They have also served as investigators, consultants, or lecturers for MSD and other manufacturers of contraceptives. BJO is an employee of MSD and may potentially own stock and/or hold stock options in the company.

\section{References}

1. United Nations Department of Economic and Social Affairs Population Division. World contraceptive use, 2011. Available from: http://www.un.org/esa/population/publications/contraceptive2011/ contraceptive2011.htm. Accessed March 26, 2014. 
2. Skouby SO. Contraceptive use and behavior in the 21 st century: a comprehensive study across five European countries. Eur J Contracept Reprod Health Care. 2004;9:57-68.

3. Trussell J. Contraceptive failure in the United States. Contraception. 2011;83:397-404.

4. Lopez LM, Grimes DA, Gallo MF, Stockton LL, Schulz KF. Skin patch and vaginal ring versus combined oral contraceptives for contraception. Cochrane Database Syst Rev. 2013;4:CD003552.

5. Davie JE, Walling MR, Mansour DJ, Bromham D, Kishen M, Fowler P. Impact of patient counseling on acceptance of the levonorgestrel implant contraceptive in the United Kingdom. Clin Ther. 1996;18: $150-159$.

6. Backman T, Huhtala S, Luoto R, Tuominen J, Rauramo I, Koskenvuo M. Advance information improves user satisfaction with the levonorgestrel intrauterine system. Obstet Gynecol. 2002;99:608-613.

7. Wysocki S. The state of hormonal contraception today: enhancing clinician/patient communications. Am J Obstet Gynecol. 2011;205: S18-S20.

8. Rosenberg M, Waugh MS. Causes and consequences of oral contraceptive noncompliance. Am J Obstet Gynecol. 1999;180:276-279.

9. Lete I, Doval JL, Perez-Campos E, et al. Factors affecting women's selection of a combined hormonal contraceptive method: the TEAM-06 Spanish cross-sectional study. Contraception. 2007;76:77-83.

10. Ahrendt HJ, Nisand I, Bastianelli C, et al. Efficacy, acceptability and tolerability of the combined contraceptive ring, NuvaRing, compared with an oral contraceptive containing 30 microg of ethinyl estradiol and $3 \mathrm{mg}$ of drospirenone. Contraception. 2006;74:451-457.

11. Archer DF, Cullins V, Creasy GW, Fisher AC. The impact of improved compliance with a weekly contraceptive transdermal system (Ortho Evra) on contraceptive efficacy. Contraception. 2004;69: 189-195.

12. Oddsson K, Leifels-Fischer B, de Melo NR, et al. Efficacy and safety of a contraceptive vaginal ring (NuvaRing) compared with a combined oral contraceptive: a 1-year randomized trial. Contraception. 2005;71: 176-182.
13. Costa ARR, Palma F, Sá JL, et al. Impact of a women's counselling programme on combined hormonal contraception in Portugal - The IMAGINE study. Eur J Contracept Reprod Health Care. 2011;16: 409-417.

14. Bitzer J, Gemzell-Danielsson K, Roumen F, Marintcheva-Petrova M, van Bakel B, Oddens BJ. The CHOICE study: effect of counselling on the selection of combined hormonal contraceptive methods in 11 countries. Eur J Contracept Reprod Health Care. 2012;17:65-78.

15. May WL, Johnson WD. A SAS macro for constructing simultaneous confidence intervals for multinomial proportions. Comput Methods Programs Biomed. 1997;53:153-162.

16. Merckx M, Donders G, Grandjean P, Van de Sande T, Weyers S. Does structured counselling influence combined hormonal contraceptive choice? Eur J Contracept Reprod Health Care. 2011;16:418-429.

17. Egarter C, Frey Tirri B, Bitzer J, et al. Women's perceptions and reasons for choosing the pill, patch, or ring in the CHOICE study: a crosssectional survey of contraceptive method selection after counseling. BMC Womens Health. 2013;13:9.

18. Gemzell-Danielsson K, Thunell L, Lindeberg M, Tyden T, MarintchevaPetrova M, Oddens BJ. Comprehensive counseling about combined hormonal contraceptives changes the choice of contraceptive methods: results of the CHOICE program in Sweden. Acta Obstet Gynecol Scand. 2011;90:869-877.

19. Egarter C, Grimm C, Nouri K, Ahrendt H-J, Bitzer J, Cermak C. Contraceptive counselling and factors affecting women's contraceptive choices: results of the CHOICE study in Austria. Reprod Biomed Online. 2012;24:692-697.

20. Merki-Feld GS, Gruber IM. Intention to use a combined contraceptive method and choice after structured counseling in Switzerland. Eur J Contracept Reprod Health Care. 2012;17:119-127.

21. Lindh I, Ellstrom AA, Blohm F, Milsom I. A longitudinal study of contraception and pregnancies in the same women followed for a quarter of a century. Hum Reprod. 2010;25:1415-1422.

22. Hardman SM, Gebbie AE. Hormonal contraceptive regimens in the perimenopause. Maturitas. 2009;63:204-212.
International Journal of Women's Health

\section{Publish your work in this journal}

The International Journal of Women's Health is an international, peerreviewed open-access journal publishing original research, reports, editorials, reviews and commentaries on all aspects of women's healthcare including gynecology, obstetrics, and breast cancer. The manuscript management system is completely online and includes
Dovepress

a very quick and fair peer-review system, which is all easy to use. Visit http://www.dovepress.com/testimonials.php to read real quotes from published authors. 